\title{
INFLUENCE OF COAL QUALITY TO THE BOILER EFFICIENCY AND OPPORTUNITY FOR ITS IMPROVEMENT
}

\author{
by \\ Lidija Joleska Bureska* \\ ELEM, TPP Bitola-Bitola, Macedonia \\ Professional paper \\ DOI: $10.5937 /$ termoteh
}

\begin{abstract}
Boiler is very important part of power plant for development of industry and production, therefore its operation need to be optimized and at the same time its efficiency. Efficiency of boiler can be determined by two methods, direct and indirect method. Mentioned two methods are providing different information. Indirect method for determination of boiler efficiency includes all heat losses in the system, while direct method did not include any heat losses. In this paper are presented changes of the boiler efficiency related with coal characteristics, determined with indirect method (according to EN 12952, part 15). Influence of different characteristics of coal such as heating value, moisture and ash content on the boiler efficiency have been evaluated. According to the results of calculations and tests, combustion coal with higher heat value, increase boiler efficiency. In the paper also is analyzed influence of the other characteristics of coal to the boiler efficiency. Comparison of the calculation results with different coal characteristics, enables proper coal selection. In order to improve boilers efficiency different opportunities have been analyzed.
\end{abstract}

Key words: boiler efficiency, Lower heating value, ash, efficiency increase, comparison.

\section{INTRODUCTION}

Boiler is a steam generating device, which produce steam with burning of fuel. In this case that is boiler with burning coal-lignite. If the coal has a higher heat value, then it is able to produce more heat per $\mathrm{kg}$ of coal. It is directly proportional to the efficiency. Efficiency of the boiler should be calculated by two methods, direct and indirect method. The both method, for calculation take into consideration a lot of parameters like pressure, temperature and flow of feed water, primary and secondary steam, coal mass flow, analyze of the flue gas, chemical analyze of the coal, ambient condition etc. Those all data are related to each other and required for calculation.

For calculation of boiler efficiency by indirect method, according EN12952, part 15, we prepare mathematical model in Microsoft Excel. Because, this method has a lot of calculations, Microsoft Excel make possible quiet easy to follow changes of the related parameters at changing of input parameters.

The calculations have been made for boiler type Pp-65, installed at TPP Bitola, for five type of coal with different Lower heat value, from 6.18 to $8.07 \mathrm{MJ} / \mathrm{kg}$ and related ultimate analyze.

At the end of this paper are presented possibilities to improve boiler efficiency by taking necessary steps on different parameters which directly affected boiler efficiency.

\section{METHODS FOR CALCULATE BOILER EFFICIENCY}

There are two methods for determine boiler efficiency: -Direct method; 
- Indirect method.

\section{Direct method}

In accordance this method, boiler efficiency is calculated with formula:

Boiler efficiency $=\frac{\text { Heat output }}{\text { Heat input }}$

In case with one reheating of the steam:

$$
h=\frac{Q_{o}}{Q_{i}}=\frac{\left[D_{s}\left(i_{s}-i_{a}\right)+D_{m}\left(i_{m 1}-i_{m 2}\right)\right]}{B_{g} \cdot H_{d}} \cdot 100
$$

Indirect method

By this method, boiler efficiency could be determinate by determining the following heat losses in the boiler:

- L1-loss due to dry flue gas:

- L2- loss due to moisture in fuel

- L3- loss due to hydrogen in fuel;

-L4- loss due to moisture in air;

- L5- loss due to unburned $\mathrm{CO}$;

- L6- loss due to enthalpy and unburned combustibles in slag and fly ash;

- L7- loss due to radiation and convection.

Boiler efficiency:

$h=100-$ Total losses $=100-\left(L_{1}-L_{2}-L_{3}-L_{4}-L_{5}-L_{6}-L_{7}\right)$

STEPS AND FORMULAS FOR DETERMINATION OF HEAT LOSSES IN THE BOILER

Step 1. Theoretical combustion air required

$$
m_{\text {Aod }}=11.5122 g C+34.2974 g H+4.3129 g S-4.3212 g O
$$

and theoretical dry flue gas:

$V_{\text {God }}=8.8930 g C+20.9724 g H+3.3190 g S-2.6424 g O+0.7997 g N$

Step 2. Percent excess air required

$$
l=\frac{y_{O 2 d}}{\left(y_{O 2 A d}-y_{O 2 d}\right)}
$$

Step 3. Real dry combustion air mass to fuel mass ratio

$$
m_{A d}=m_{A o d}+r_{n A d} \cdot V_{G o d} \cdot \frac{y_{O 2 d}}{y_{O 2 A d}-y_{O 2 d}}
$$

For real dry flue gas:

$$
V_{G d}=V_{G o d} \cdot \frac{y_{O 2 A d}}{y_{O 2 A d}-y_{O 2 d}}
$$

For wet flue gas:

$$
m_{G}=m_{A}+1-g_{A s h} \cdot(1-n)+m_{A S}
$$


For dry flue gas:

$$
m_{G d}=m_{G}+m_{H 2 O}
$$

Step 4. Total heat input

$$
Q_{(N) t o t}=m_{F} \cdot H_{(N) t o t}+Q_{(N) z}
$$

Step 5. Heat losses

1. Heat loss due to dry flue gas

$$
Q_{(N) G}=m_{G d} \cdot c_{p} \cdot G_{d} \cdot\left(t_{g}-t_{r}\right) \quad \text { or } \quad L_{1}=\frac{Q_{(N) G}}{H_{(N) t o t}}
$$

2. Heat loss due to evaporation of moisture in coal

$$
g_{H 2 O} \cdot c_{p S T} \cdot\left(t_{g}-t_{r}\right) \quad \text { or } \quad L_{2}=\frac{g_{H 2 O} \cdot c_{p S T} \cdot\left(t_{g}-t_{r}\right)}{H_{(N) t o t}}
$$

3. Heat loss due to evaporation of water formed due to $\mathrm{H}_{2}$ in coal

$$
9 g_{H} \cdot c_{p S T} \cdot\left(t_{g}-t_{r}\right) \quad \text { or } \quad L_{3}=\frac{9 g_{H} \cdot c_{p S T} \cdot\left(t_{g}-t_{r}\right)}{H_{(N) t o t}}
$$

4. Heat loss due to the moisture in combustion air

$$
x_{H 2 O A d} \cdot m_{G d} \cdot c_{p S T} \cdot\left(t_{g}-t_{r}\right) \quad \text { or } \quad L_{4}=\frac{x_{H 2 O A d} \cdot m_{G d} \cdot c_{p S T} \cdot\left(t_{g}-t_{r}\right)}{H_{(N) t o t}}
$$

5. Heat loss due to the unburned $\mathrm{CO}$ in flue gas

$$
J_{C O}=V_{G d} \cdot y_{C O d} \cdot H_{C O n} \quad \text { or } \quad L_{5}=\frac{V_{G d} \cdot y_{C O d} \cdot H_{C O n}}{H_{(N) t o t}}
$$

6. Heat loss due to the unburned in slag and fly ash

$$
Q_{S F}=Q_{S L}+m_{F} \cdot J_{F A} \quad \text { or } \quad L_{6}=\frac{Q_{S F}}{H_{(N) t o t}}
$$

7. Heat loss due to the radiation and convection

$$
Q_{R C}=\frac{C \cdot Q_{N}^{0.7}}{m_{F}} \quad \text { or } \quad L_{7}=\frac{Q_{R C}}{H_{(N) t o t}}
$$

Step 6. Sum of all heat losses $=L 1+L 2+L 3+L 4+L 5+L 6+L 7[\%]$

Step 7. Determine boiler efficiency

$$
h=100-\left(L_{1}+L_{2}+L_{3}+L_{4}+L_{5}+L_{6}+L_{7}\right)
$$




\section{INPUT DATA AND RESULTS FROM THE TEST}

Table 1: Parameters on boiler during testing [1]

\begin{tabular}{|l|c|c|}
\hline Parameters & Unit & Value \\
\hline Steam production & $\mathrm{t} / \mathrm{h}$ & 703.3 \\
\hline Pressure of primary steam & $\mathrm{MPa}$ & 13.43 \\
\hline Temperature of primary steam & ${ }^{\circ} \mathrm{C}$ & 540 \\
\hline Coal mass flow & $\mathrm{t} / \mathrm{h}$ & 281 \\
\hline Lower heat value of coal & $\mathrm{MJ} / \mathrm{kg}$ & 8 \\
\hline Temperature of feed water & ${ }^{\circ} \mathrm{C}$ & 236 \\
\hline
\end{tabular}

The test has been done on boiler 3 in TPP Bitola with coal marked "coal 1". Some of parameters received during the test are showed in Table 1. Those data were used for the next calculations, only coal was changed and according prepared Microsoft Excel program were determined heat losses and boiler efficiency for suitable coal. Ultimate analyze of different coals are showed in Table 2.

Table 2: Ultimate analyze of coals [3]

\begin{tabular}{|l|c|c|c|c|c|c|}
\hline Parameters & Coal 1 & Coal 2 & Coal 3 & Coal 4 & Coal 5 & Coal 6 \\
\hline $\mathrm{W}[\%]$ & 55.9 & 49 & 52.25 & 49.5 & 48.06 & 43.83 \\
\hline $\mathrm{A}[\%]$ & 6.6 & 20 & 13.5 & 12.4 & 26.15 & 25.65 \\
\hline $\mathrm{C}[\%]$ & 24.5 & 19.7 & 22.5 & 25.1 & 15.98 & 18.91 \\
\hline $\mathrm{H}[\%]$ & 1.96 & 1.9 & 1.93 & 1.95 & 1.5 & 1.77 \\
\hline $\mathrm{S}[\%]$ & 0.25 & 0.7 & 0.57 & 0.76 & 0.56 & 0.61 \\
\hline $\mathrm{O}[\%]$ & 10.29 & 8.4 & 8.25 & 9.87 & 7.33 & 8.73 \\
\hline $\mathrm{N}[\%]$ & 0.5 & 0.3 & 1 & 0.42 & 0.42 & 0.49 \\
\hline $\mathrm{Hd}[\mathrm{MJ} / \mathrm{kg}]$ & 8.00 & 6.18 & 7.31 & 8.07 & 6.55 & 6.84 \\
\hline
\end{tabular}

\section{Ash analysis}

During calculation of boiler efficiency with coals 2,3,4,5 and coal 6, are dopted the same analysis of the slag and fly ash, like analysis during testing with coal 1 , and:

- ash temperature $t_{S l}=800\left[{ }^{\circ} \mathrm{C}\right]$,

- ash heat value $H_{u u}=27.2[\mathrm{MJ} / \mathrm{kg}]$ (according EN 12951-15).

\section{RESULTS}

From the results shown in Table 3 , can be seen that the biggest changes of the boiler efficiency are result of changes of the heat losses L1 and L6, that is heat losses due to dry gas and unburned in the slag and fly ash. At Figure 1, are presented changes of the boiler efficiency caused by changes of above mentioned heat losses.

Table 3: Results from calculations

\begin{tabular}{|l|c|c|c|c|c|c|}
\hline Parameters & Coal 1 & Coal 2 & Coal 3 & Coal 4 & Coal 5 & Coal 6 \\
\hline $\mathrm{L}_{1}[\%]$ & 8.00 & 8.69 & 8.32 & 8.22 & 6.60 & 7.45 \\
\hline $\mathrm{L}_{2 \mathrm{c}}[\%]$ & 2.31 & 2.61 & 2.36 & 2.03 & 2.42 & 2.11 \\
\hline $\mathrm{L}_{3 c}[\%]$ & 0.73 & 0.91 & 0.78 & 0.72 & 0.68 & 0.77 \\
\hline $\mathrm{L}_{1}+\mathrm{L}_{2}+\mathrm{L}_{3}+\mathrm{L}_{4}[\%]$ & 0.17 & 0.19 & 0.18 & 0.18 & 0.14 & 0.16 \\
\hline $\mathrm{L}_{5}[\%]$ & 11.21 & 12.40 & 11.64 & 11.14 & 9.84 & 10.49 \\
\hline $\mathrm{L}_{6 c}[\%]$ & 0.03 & 0.03 & 0.03 & 0.03 & 0.02 & 0.03 \\
\hline $\mathrm{L}_{7}[\%]$ & 1.27 & 3.89 & 2.38 & 2.05 & 4.78 & 4.49 \\
\hline $\mathrm{h}[\%]$ & 0.41 & 0.39 & 0.41 & 0.41 & 0.40 & 0.40 \\
\hline
\end{tabular}

From Figure 2, can be seen that when boiler for combustion use coal with high value of Lower heat value, then his efficiency is high and opposite.

One of the parameter which have the biggest influence to the boiler efficiency is the ash contain in the coal.

This influence is shown on Figure 3.

Influence of the moisture contain in the coal on the boiler efficiency is shown on the Figure 4, there can be noticed that with increasing of moisture contain in coal, is increasing the boiler efficiency. This case is opposite from the case when should be compared coals with the same ash contain, and if different is only moisture contain, 


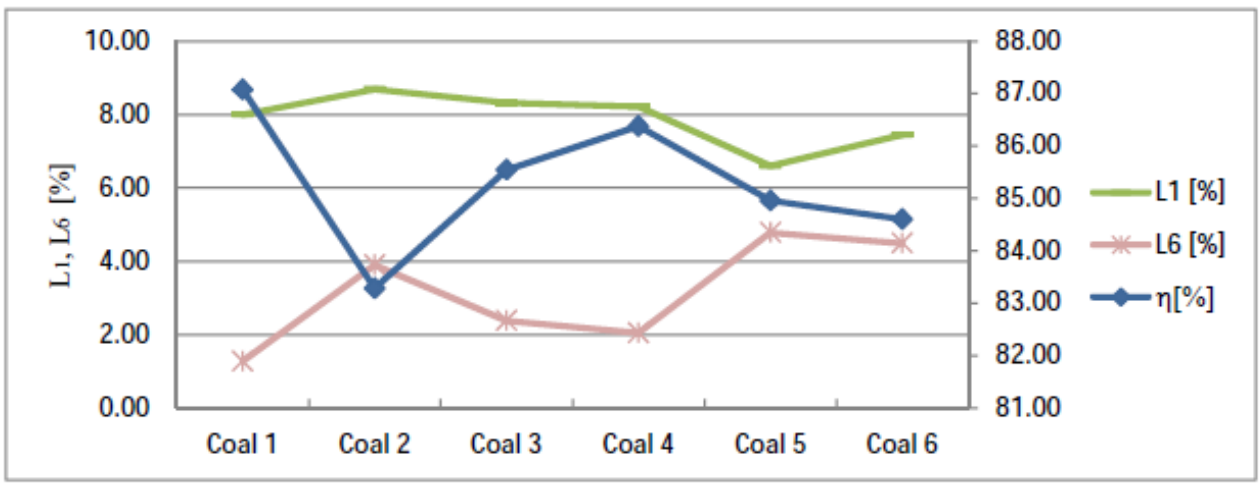

Figure 1: The dependence of boiler efficiency by changes of heat losses due to dry gas and unburned in the slag and ash

and there increasing moisture contain in the coal, cause reducing of boiler efficiency and opposite. In the case shown on Figure 4, situation is deferent, because in the comparative coals, some of them have lower moisture contain but ash contain is high and then reduces Lower heat value of coal and in the same time reduces boiler efficiency.

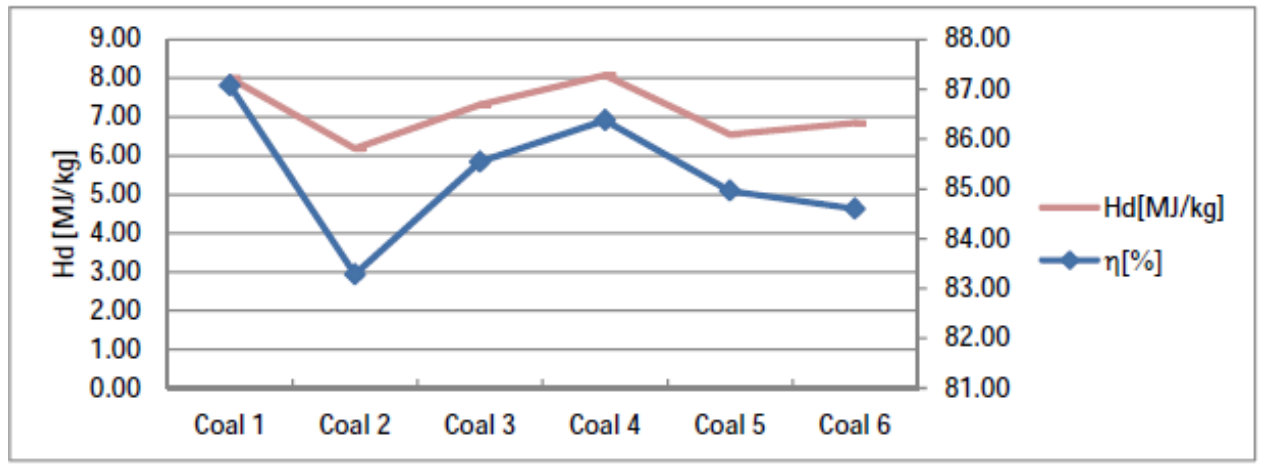

Figure 2: The dependence of boiler efficiency by low heat value of coal

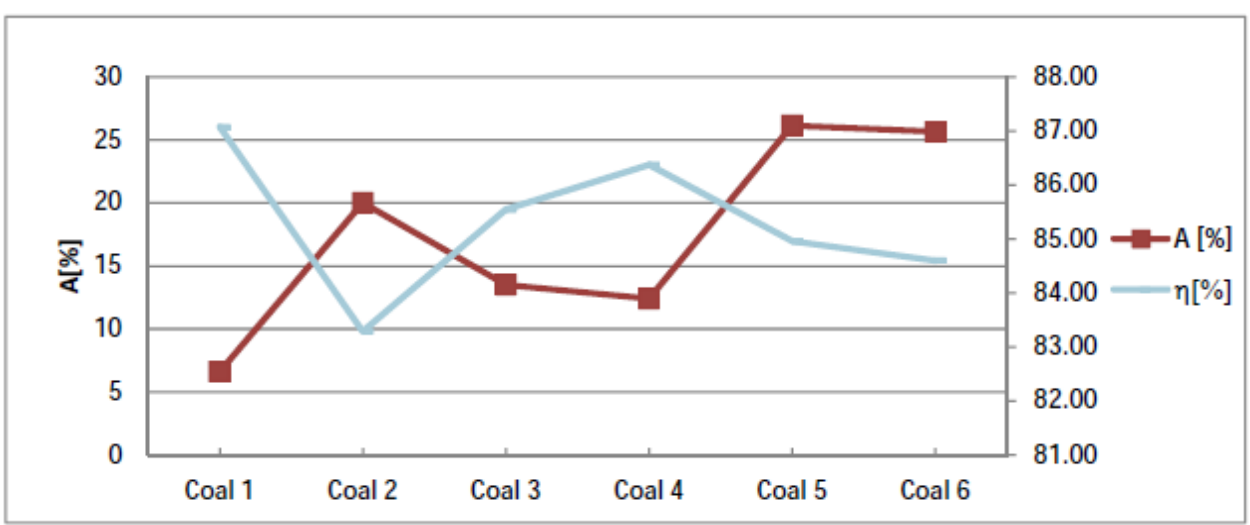

Figure 3: The dependence of boiler efficiency by ash contain in coal 


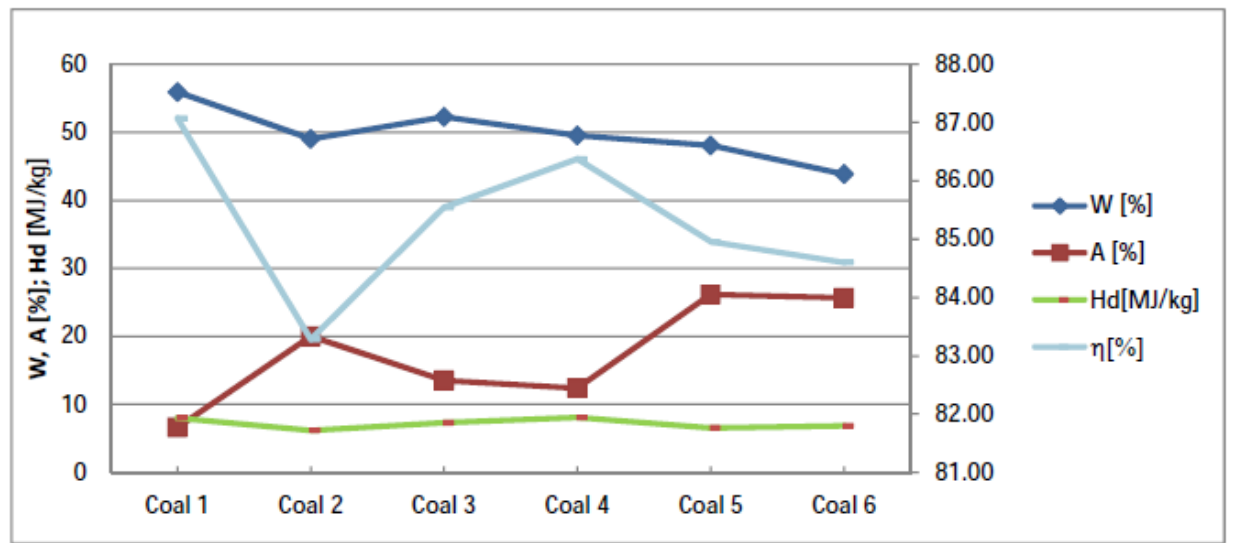

Figure 4: The dependence of boiler efficiency by moisture contain in coal

\section{THE OPPORTUNITY FOR IMPROVEMENT BOILER EFFICIENCY}

\section{The proper coal preparation}

The proper coal preparation, mean coal without foreign parts (stones, steel parts, etc.), clean from dirt and dust with moisture and ash content within the design range. Dimension of the coal pieces have to be in accordance with design, because bigger pieces cause problems in the milling system. It is known that milling system directly have influence of the boiler efficiency because with better milling, in the boiler has better combustions with reduced loss due to the unburned in the slag and fly ash. About influence of the ash and moisture we explained above.

In the coal preparation belong and milling system. For better milling is very important maintenance of the mills, that mean regular control and repairing of the wear part in order to keep good clearances.

\section{Elimination the incomplete combustion}

Heat production in the boiler depends on combustion. In order to have organized combustion is very important to eliminate reasons which bring incomplete combustion, that mean:

- control of the false air in the furnace,

- optimal relation coal-air-water,

- to keep the necessary velocity of the secondary air,

- good distribution of the air mixture to the burner levels etc.

\section{Elimination of slagging on the heating surfaces in the boiler}

Deposit on the heating surfaces in the boiler cause reduction of heat exchange as well as reduction of steam temperature in one part of the boiler and increase in other part. With unequal temperature distribution in the boiler heat surfaces, boiler work with reduced load and reduced efficiency.

\section{Implementation of the automatic control system}

The automatic control system, DCS (digital control system) for combustion is efficient, reliable and flexible. DCS of the boiler reduces personnel influence (influence of the operators) on the boiler operation and enables a higher efficiency of the boiler. DSC collects and analyzes all continuous measurements of temperature, pressure and flow, measurement of oxygen along the gas ducts etc. and after that operates with boiler.

\section{Installation of the frequency regulation of drivers}

The frequent driver regulation of induced fans, pumps for feed water and other pumps, mills (if its type allow), provide better speed control and reduction of power self-consumption. Because the power consumption is function 
of the speed, then a small speed decrease significantly would reduce power consumption. In the calculation of the boiler efficiency, power consumption is included in credits calculation. Equipment which is included for credits calculation depends of the envelope boundary covered by the heat balance of the steam generator.

\section{CONCLUSIONS}

From the above mentioned calculations and analyses we can conclude that combustion of coal with higher value of Lower heat value, lower ash contain and lower moisture, enables a high boiler efficiency. Here when we used for calculation coals with Lower heat value $8.0 ; 7.31$ and $8.07 \mathrm{MJ} / \mathrm{kg}$, following corresponding values of boiler efficiency have been obtained: $87.07 ; 85.54$ and $86.37 \%$. When we used coals with high ash contain 20.00; 26.15 and $25.65 \%$ then boiler efficiency was lower: $83.28 ; 84.86$ and $\%$.

The prepared program for calculation of the boiler efficiency by indirect method enables to record every change of efficiency by adding different values of the data. Its use is easy and quickly as well as proper diagrams could be prepared.

\section{REFERENCES}

[1] , Measuring report -TPP Bitola - Unit 3. 2013.

[2] , European Standard - EN 12952-15. 2003.

[3] S. Pecakov, Local instruction for exploitation stem boiler. Pp-700-13, 8-545 (P65).

[4] I.J. Petrovski, Steam boilers. Skopje. 2004.

[5] L.J. Bureska, Optimization of pulverized coal combustion in the furnace of utilities boilers. Skopje: University "Sts Cyril and Methodius". 2013. Ph. D. Thesis.

[6] T. Cheten, K. Bhavesh and K. Vijay, "Efficiency with different GCV of coal and efficiency improvement opportunity in boiler." International journal of innovative research in science, engineering and technology, vol. 2, br. 5. May, 2013

[7] A. Senegacnik, I. Kosutrin and M. Sekavcnik, "Accuracy improvement analysis of the standard indirect method for determination a steam boiler's efficiency." VGB Power Tech, br. 12, 2008

Paper submitted: Paper revised: Paper accepted:
Copyrights ${ }^{\odot} 2017$ Society of Thermal Engineers of Serbia Published by the VINCA Institute of Nuclear Sciences. Belgrade. Serbia This is an open access article distributed under the CC BY-NC-ND 4.0 terms and conditions 